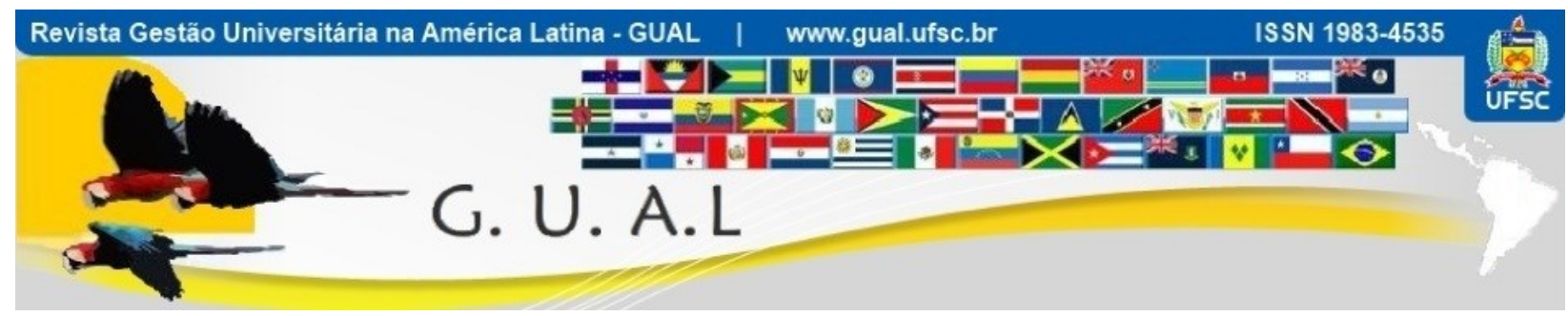

DOI: http://dx.doi.org/10.5007/1983-4535.2015v8n3p184

\title{
FATORES QUE INFLUENCIAM A DECISÃO DE ESCOLHA PELO CURSO DE CIÊNCIAS CONTÁBEIS POR ALUNOS DE IES NA CIDADE DE SÃO PAULO
}

\section{FACTORS THAT INFLUENCE STUDENTS DO TAKE AN ACCOUNTANCY COURSE IN SÃO PAULO CITY UNIVERSITIES}

\author{
Ivam Ricardo Peleias, Doutor \\ Fundação Escola de Comércio Álvares Penteado - FECAP \\ ivamrp@fecap.br \\ Caroline do Amaral Nunes, Mestre \\ Fundação Escola de Comércio Álvares Penteado - FECAP \\ caroline.nunes@ffecap.br
}

Recebido em 09/junho/2014

Aprovado em 15/julho/2015

Sistema de Avaliação: Double Blind Review

Esta obra está sob uma Licença Creative Commons Atribuição-Uso. 


\title{
RESUMO
}

A adolescência é um momento de decisões para o jovem e implica em escolher caminhos, renunciando a outras opções. É a fase da vida na qual surgem as primeiras cobranças sobre sua escolha profissional. Vários fatores influenciam esta escolha. Dentre as várias alternativas existentes para o exercício de uma profissão regulamentada, é possível vir a ser contador. Dois fatores relevantes podem influenciar na escolha: a IES em que o jovem realiza o curso superior e a localidade em que reside. Buscou-se investigar e analisar os fatores que influenciaram a decisão de escolha de um grupo de jovens pelo ingresso no curso de graduação em Ciências Contábeis. Foram realizadas entrevistas de profundidade com estudantes do $1^{\circ}$ semestre do curso, três da FECAP e três da PUC-SP. Aplicou-se a técnica de análise de conteúdo para interpretar os achados. O fator mais influente relatado é a empregabilidade, seja pela crença de que não faltará emprego, ou porque os entrevistados já estão empregados na área. Diferente do quanto apontado em parte da literatura, constatou-se que os pais não exercem influência direta na escolha do curso dos entrevistados. Os achados estimulam a continuidade das investigações, para aprofundar questões relativas a empregabilidade e a dos entrevistados sobre o mundo do trabalho, bem como a realização de investigações com amostras maiores, para confirmar ou não os resultados encontrados.

Palavras-chave: Carreira. Contabilidade. Empregabilidade. Profissão. Mundo do Trabalho.

\begin{abstract}
Adolescence is a period of time when teenagers need to make decisions and choose their own ways, at the resignings of other options. That is the time when they have to deal with the first demands in their professional choice. Many factors influence this choice. One of the possible existing alternatives for a regulated carreer is to become an accountant. Two important factors may influence this choice: the university which the students take their graduation course and the place where they live. In this context, the aim of this research was to investigate and analyse factors that influence the decision of a group of students Who attend an Accountancy Course. It was made deep interviews with first semester students, three from FECAP and other three from PUC-SP, two Brazilian universities. The content analysis was applied so as to interpret the results. The most influent factor was the employability, as some students believe they will have a future job or because many are already working in the area. Differently from litterature, it was stated that parents do not influence directly in students' choice of a course. The results encourage more investigations, to deepen matters related to employability and the students concernig the Job Market. Moreover, it encourages bigger sample researches, to confirm or not the results.
\end{abstract}

Key-words: Carreer. Accountancy. Employability. Job. Job market. 


\section{INTRODUÇÃO}

A adolescência é um período de mudanças marcantes. $\mathrm{O}$ adolescente não é um adulto formado, mas ainda não deixou de ser criança completamente. É um momento de decisões importantes e implica em escolher um caminho, muitas vezes abdicando de outras opções (SANTOS, 2005). É durante o Ensino Médio que surgem as primeiras cobranças sobre o jovem em relação à escolha profissional.

A escolha é significativa, de longo prazo e pode parecer definitiva. Vários fatores influenciam a decisão: religião, valores, crenças, situação econômica e política do país, características pessoais, condições sociais, família, entre outros (SANTOS, 2005). As influências sociais e dos pares, inclusive as exercidas pelos pais, são as que mais pesam no momento da decisão do adolescente sobre qual profissão seguir (ALMEIDA; PINHO, 2008).

Ao escolher uma profíssão, o jovem inicia seu preparo para ingressar no curso de graduação e a planejar a carreira profissional (SOUSA, 2007). Dentre as alternativas profissionais existentes no Brasil, interessa a de Contador. O exercício das atividades contábeis é prerrogativa do Contador registrado no Conselho Regional de Contabilidade de seu estado (BRASIL, 1946). Ao término do curso de Ciências Contábeis, o egresso poderá atuar como autônomo, empregado, servidor público, militar ou empresário (CFC, 1983).

As matrículas no curso superior em Ciências Contábeis no Brasil aumentaram, em média, 7\% ao ano entre 2001 e 2009; porém, apenas 14\% dos matriculados concluíram os estudos (INEP, 2009; PINHEIRO, 2008). Vários motivos levam à evasão do curso. Dentre estes se destaca o fato do aluno não ter as expectativas atendidas em relação à sua formação, à instituição, a carreira pretendida, além da falta de conhecimento sobre o curso, a profissão e “vocação" (DIAS; THEÓPHILO; LOPES, 2010; MORAES; THEÓPHILO, 2006; SILVA FILHO et al., 2007).

Há algum tempo, pesquisas e entrevistas afirmavam que a contabilidade seria a profissão do século XXI. Hoje, no século XXI, a contabilidade é uma profissão relevante. Já se falou e se demonstrou a importância da Contabilidade para os agentes econômicos (LOPES; IUDÍCIBUS; MARTINS, 2008).

A procura pelo curso superior em Ciências Contábeis, no Brasil, vem crescendo nos últimos anos. Dados do INEP (2013) indicam um crescimento médio de 5,3\% ao ano entre 2006 e 2012, somente entre os cursos presenciais, e vários podem ser os fatores que levam a 
este crescimento. A quantidade de matrículas em instituições de ensino superior (doravante IES), conforme o levantamento do INEP, está apresentada na tabela 1.

Tabela 1 Matrículas no curso de Ciências Contábeis e- Geral e IES particulares

\begin{tabular}{c|c|c|c|c|c|c}
\hline \multirow{2}{*}{ Ano } & \multicolumn{6}{|c}{ Matrículas } \\
\cline { 2 - 7 } & Geral & Evolução \% & Públicas & Evolução \% & Particulares & Evolução \% \\
\hline $\mathbf{2 0 0 6}$ & 179.294 & & 85.175 & & 94.119 & \\
\hline $\mathbf{2 0 0 7}$ & 190.971 & $6,51 \%$ & 84.200 & $-1,14 \%$ & 106.771 & $13,44 \%$ \\
\hline $\mathbf{2 0 0 8}$ & 204.553 & $7,11 \%$ & 85.244 & $1,24 \%$ & 119.309 & $11,74 \%$ \\
\hline $\mathbf{2 0 0 9}$ & 205.330 & $0,38 \%$ & 72.173 & $-15,33 \%$ & 133.157 & $11,61 \%$ \\
\hline $\mathbf{2 0 1 0}$ & 224.228 & $9,20 \%$ & 42.049 & $-41,74 \%$ & 182.179 & $36,82 \%$ \\
\hline $\mathbf{2 0 1 1}$ & 239.488 & $6,81 \%$ & 45.237 & $7,58 \%$ & 194.251 & $6,63 \%$ \\
\hline $\mathbf{2 0 1 2}$ & 249.529 & $4,19 \%$ & 49.608 & $9,66 \%$ & 199.921 & $2,92 \%$ \\
\hline Média & $\mathbf{2 1 3 . 3 4 2}$ & $\mathbf{5 , 3 2 \%}$ & $\mathbf{6 6 . 2 4 1}$ & $\mathbf{- 6 , 6 2 \%}$ & $\mathbf{1 4 7 . 1 0 1}$ & $\mathbf{1 3 , 8 6 \%}$ \\
\hline
\end{tabular}

Fonte: Adaptado de INEP (2013)

Os dados do INEP revelam um aumento médio de 5,32\%, constatando-se o crescimento nas IES privadas e o decréscimo nas públicas. No período apresentado, o curso de graduação em Ciências Contábeis foi o sexto com maior número de matrículas no país, tendo 249.342 alunos em 2012. À época desta pesquisa, 247 IES eram reconhecidas no Brasil oferecendo o curso de Ciências Contábeis, nas modalidades "presencial" e "à distância". Destas, 73 (cerca de 29\%) estão ativamente estabelecidas na cidade de São Paulo (INSTITUIÇÕES..., 2013).

O cenário descrito justifica investigar os fatores que influenciam a decisão de escolha pelo curso de Ciências Contábeis. Desde o início da pesquisa, não foram localizados trabalhos de mesma natureza na capital paulista. Após convalidar cidade de São Paulo como lócus de pesquisa, decidiu-se realizar o estudo em duas etapas. Uma inicial, com grupos iguais de alunos de duas IES privadas, para melhor conhecer a região objeto da pesquisa. Os resultados obtidos serão usados para uma segunda fase, de maior abrangência, considerando os achados na primeira etapa.

Pelo exposto, formulou-se e buscou-se a resposta à seguinte questão de pesquisa: Quais fatores influenciaram a decisão de escolha de um grupo de estudantes de duas IES privadas da cidade de São Paulo pelo ingresso no curso de graduação em Ciências Contábeis? 
O objetivo é identificar e descrever os fatores que influenciaram a decisão de escolha de seis estudantes pelo ingresso no curso de Ciências Contábeis em duas IES privadas da cidade de São Paulo. Espera-se obter subsídios relevantes para a continuidade da investigação, além de auxiliar as IES a elaborar seus projetos pedagógicos, tornando-os mais próximos do perfil dos ingressantes, por meio da obtenção e direcionamento de informações sobre o curso de Ciências Contábeis aos candidatos ao vestibular.

\section{REFERENCIAL TEÓRICO}

\subsection{FATORES QUE INFLUENCIAM A ESCOLHA DA CARREIRA}

Profissão e carreira são termos comumente confundidos por se relacionarem ao trabalho. Conceituar profissão não é uma tarefa fácil e pouco consenso se chegou sobre o assunto (BYALIN, 1980; KHOURY, 1978). Porém, é possível considerar quatro características essenciais de uma profissão: a) possui profunda base de conhecimento; b) está acima dos próprios interesses, pois é de interesse geral; c) há o controle da profissão e dos pares por um código de ética; e d) existe o recebimento de honorários pela prestação de serviços (LÜDKE; BOING, 2004). O termo "carreira" origina-se do latim medieval via carraria, que significa um caminho rústico para carruagens (BALASSIANO; VENTURA; FONTES FILHO, 2004). Na forma atualmente empregada, como trajetória profissional, quer dizer "um ofício, uma profissão que apresenta etapas, uma progressão" (CHANLAT, 1995). Yusoff et al. (2011) afirmam de forma enfática que a carreira é um projeto de longo prazo.

Uma das primeiras decisões importantes para um adolescente é escolher a profissão, que lhe aparenta ser definitiva, pois parece ser por tempo indeterminado (ALMEIDA; PINHO, 2008). Ao encarar a decisão de escolher uma profissão, o adolescente se vê em conflito com seus interesses e aptidões. Ele se questiona sobre seus anseios de "quem ser" e "quem não ser". Acima de tudo, ao ser perguntado sobre seus objetivos futuros, em orientações vocacionais, responde que "deseja ser feliz" sem saber, muitas vezes, como. "Para o adolescente, o futuro é uma carreira, uma universidade, professores, colegas, etc. (...) é também, para ele, uma família e a sua inclusão no sistema produtivo da sociedade em que vive" (BOHOSLAVSKY, 1995). É um momento de renúncias e para a maioria dos jovens, uma atividade exploratória, não correspondendo a um projeto de vida mais reflexivo e elaborado (TEIXEIRA; GOMES, 2004). 
É surpreendente constatar que o adolescente, em fase de mudanças em tantas outras áreas, como religião e ética, também deve realizar uma escolha tão importante quanto definir uma profissão. Neste momento o adolescente se apoia em vários fatores para lhe ajudar a escolher a profissão: "vocação", a combinação de sua história, genética, escolhas pessoais, culturais e principalmente familiares, pois os pais são os primeiros pilares de apoio a serem usados (ALMEIDA; PINHO, 2008; MOURA; SILVEIRA, 2002).

Os fatores podem ser divididos em três grupos: internos, externos e terceiros. Como fatores internos, entendem-se os pessoais, interesses individuais, valores e aptidões que formam uma preferência vocacional. Neste ponto, o adolescente possui uma ideia sobre o tipo de pessoa que ele pensa ser (BALBINOTTI, 2003). Super (1980) denomina esse processo como um modelo fenomenológico, de clareza de autoconceito e por ele faz uma ligação dos traços pessoais do indivíduo com seu desenvolvimento pessoal. A clareza de autoconceito refere-se às certezas que o indivíduo possui sobre si próprio e, em que medida elas estão definidas, pois são fundamentais para a decisão de carreira (TEIXEIRA; GOMES, 2005).

A teoria da expectativa de auto-eficácia (BANDURA, 2001; LENT; BROWN; HACKETT, 1994) apresenta a proposta de que os indivíduos creem na própria capacidade de executar com sucesso um determinado comportamento, o que se reveste em um fator decisivo para escolher e desenvolver a carreira (NUNES; NORONHA, 2009; TEIXEIRA; GOMES, 2005). Esta teoria prevê que os interesses específicos do adolescente, seu desempenho escolar e disciplinas favoritas desencadeiam as opções de carreira por ele consideradas como as mais propensas a se obter sucesso. Assim, o indivíduo poderá ter maior expectativa de sucesso nas áreas em que tiver maior auto-eficácia (NUNES; NORONHA, 2009).

Como fator de terceiros há a influência dos pares e dos familiares na escolha da carreira e do curso pelo adolescente. É importante para o adolescente que a família aceite sua decisão de escolha. Por esse motivo a família também sofre, de forma direta ou indireta, sendo atingida pelo momento de dúvida do adolescente, em especial nas situações em que alguns pais procuram se realizar profissionalmente nos filhos (BOHOSLAVSKY, 1995; ALMEIDA; PINHO, 2008), enquanto outros se desgastam com as dificuldades que o adolescente tem em se decidir (SANTOS, 2005).

Ao realizar sua escolha, o adolescente procura fazê-la dentro dos padrões de valores de sua família (ALMEIDA; PINHO, 2008). Santos (2005) realizou um estudo com 16 exorientandos de um programa de orientação profissional de uma IES pública federal e 
demonstrou que os jovens tendem a buscar primeiro o apoio familiar na escolha da profissão a seguir. A influência dos pais começa na infância, pois são eles que proporcionarão apoio financeiro, formação educacional, aprovação ou reprovação das escolhas (ALMEIDA; MELO-SILVA, 2011).

\subsection{O MUNDO DO TRABALHO E AS ALTERNATIVAS DE ATUAÇÃO DO CONTADOR}

O terceiro grupo de fatores que influenciam no processo de decisão da escolha da profissão são os externos. As possibilidades de sucesso profissional, prestígio e as opções de carreira são fatores considerados pelos adolescentes no momento da escolha da profissão. Da mesma forma, o mercado de trabalho não pode ser ignorado nas escolhas do curso universitário e da carreira profissional (BOMTEMPO, 2005). Uma opção que o adolescente possui é o curso de Ciências Contábeis.

O ensino da Contabilidade no Brasil iniciou-se em 1809 com as "Aulas de Comércio", regulamentadas em 1846 pelo Decreto $\mathrm{n}^{\circ}$ 456, no Rio de Janeiro. As aulas eram ministradas por dois anos e possuíam disciplinas como Direito Comercial, Prática das Principais Operações e Atos Comerciais e a Arte da Arrumação de Livros. Com as mudanças comerciais e políticas do país, dezessete anos após o governo imperial identificou a necessidade de mudanças no curso e aumentou os estudos para quatro anos. Em 1905, o Decreto ${ }^{\circ}{ }^{0} 1339$ reconheceu oficialmente os diplomas de formação geral e prática e outro de nível superior. $\mathrm{O}$ mesmo Decreto reconheceu a atuação da Escola Prática do Comércio de São Paulo, fundada em 1902, posteriormente denominada Fundação Escola de Comércio Álvares Penteado (PELEIAS et al., 2007).

Em 1926, o Decreto $n^{\circ} 17.329$ regulamentou o ensino técnico profissionalizante e em 1946, foi instituída a Faculdade de Ciências Econômicas e Administrativas - FCEA, da Universidade de São Paulo - USP. No mesmo ano a profissão contábil passou a ser regulamentada pelo Decreto-Lei $\mathrm{n}^{\circ}$ 9.295, o qual estabeleceu o registro do profissional técnico ou contador nos Conselhos Regionais de Contabilidade. O Censo da educação superior, em 2009, apontou o curso de Ciências Contábeis como o $6^{\circ}$ com maior número de matrículas no país, com 235.274 alunos (INEP, 2009). Ao início desta pesquisa, 247 IES reconhecidas no Brasil ofereciam o curso de Ciências Contábeis, nas modalidades presencial e à distância, sendo que 73 (29\%), estão estabelecidas no município de São Paulo (E-MEC, 2013). 
Ao fim do curso, o egresso deve ser aprovado no exame de suficiência, promovido pelo Conselho Federal de Contabilidade. Esta aprovação o torna apto a exercer a profissão de contador, atuando como autônomo, empregado, servidor público, militar ou empresário, nas funções de analista, assessor, assistente, auditor interno ou externo, conselheiro, consultor, controller, legislador, perito, pesquisador, professor, entre outros (CFC, 1983). Além dos vários caminhos que a carreira contábil oferece, também influencia na escolha a oferta de trabalho na área contábil. Estudo realizado na Turquia mostra que os três fatores que mais influenciam os jovens a escolherem o curso de contabilidade são: interesse pela contabilidade, oportunidade de trabalho percebida e aptidão (UYAR; GÜNGÖRMÜS; KUZEY, 2011).

Há um vasto campo de trabalho na profíssão contábil. Peleias et al. (2008) levantaram 4.017 anúncios de emprego em contabilidade publicados em três jornais de grande circulação na cidade de São Paulo entre março de 2004 e junho de 2005. Constataram que, na medida em que os anúncios evoluíram na estrutura organizacional, aumentavam as exigências de habilidades gerenciais, sem que houvesse o decréscimo das habilidades contábeis inerentes aos contadores de nível superior. Isto porque não é preciso que o profissional se isole em especializações para garantir sua empregabilidade (PELEIAS et al. 2011). Pires, Ott e Damacena replicaram a pesquisa em Porto Alegre, identificando 1.106 anúncios em um jornal de grande circulação e um site de empregos no período de janeiro a setembro de 2007 (2009).

Pesquisa de Burnett (2003) no Texas - Estados Unidos aponta que os empregadores procuram como habilidades nos profissionais contábeis: capacidade de análise, pensamento crítico, boa comunicação escrita e oral, trabalho em equipe, iniciativa para tomada de decisões, habilidade nas novas tecnologias e ética profissional. Este é um exemplo de perfil profissional que o mundo do trabalho procura, quando as organizações estão interessadas em encontrar empregados. Além de ser empregado o profissional também pode atuar como empregador (ou empreendedor), vinculando o mundo do trabalho e a prática social à educação recebida durante o curso escolhido (BRASIL, 1996).

Atuar na área contábil era, há alguns anos, uma atividade exclusiva do gênero masculino. Nos últimos anos as mulheres vêm alcançando seu espaço no mundo do trabalho, que se apresenta promissor para ambos os gêneros (KOLLING; BIERGER; SEIBERT, 2010).

Pesquisas da Fundação Carlos Chagas (2013) apontam que as mulheres estudam cerca de nove anos a mais do que os homens. Neste sentido as mulheres se preocupam mais em realizar-se academicamente acreditando alcançar, assim, seu crescimento profissional 
(FLECK; WAGNER, 2003). Elas já são maioria no ingresso e conclusão dos cursos universitários, inclusive nas áreas das Ciências Sociais, Negócios e Direito (INEP, 2009). Apesar de serem maioria, as mulheres representam, atualmente, 1/3 dos profissionais contábeis registrados no Conselho Regional de Contabilidade de São Paulo ([2012]).

\section{METODOLOGIA DA PESQUISA E LIMITAÇÕES}

Esta pesquisa é uma investigação com alunos ingressantes no curso de Ciências Contábeis. Buscou-se verificar os determinantes que levaram os jovens a ingressar no curso, bem como seus conhecimentos sobre a área contábil antes do início da graduação. A escolha do público-alvo e das estratégias de pesquisa justifica-se porque os resultados aqui obtidos serão usados como base para uma pesquisa maior, mais aprofundada e abrangente.

A população alvo são os alunos matriculados no $1^{\circ}$ semestre letivo do curso de Ciências Contábeis de duas IES privadas da cidade de São Paulo: Pontifícia Universidade Católica de São Paulo - PUC-SP e Fundação Escola do Comércio Álvares Penteado FECAP. Estas IES foram escolhidas tendo como principais motivos: as avaliações recebidas pelo Ministério da Educação no Conceito Institucional, com nota 4 para ambas, em uma escala de valor máximo 6 (E-MEC, 2013); ambas são reconhecidas pela formação oferecida aos futuros contadores; a a acessibilidade junto aos alunos. À época desta etapa da pesquisa, a PUC-SP possuía 45 alunos e a FECAP 50 matriculados no $1^{\circ}$ semestre, uma população de 95 estudantes.

Foram entrevistados sete alunos, três da PUC-SP e quatro da FECAP, que aceitaram participar de forma voluntária, perfazendo $6,3 \%$ da população alvo. Uma entrevista realizada na FECAP foi descartada, pois o respondente afirmou não gostar do curso e que trancaria a matrícula em alguns dias. As entrevistas de profundidade foram realizadas com os alunos selecionados durante os intervalos de suas aulas. Foram gravadas, transcritas e posteriormente validadas pelos sujeitos, permitindo o desenvolvimento da investigação por meio do método de análise de conteúdo (GODOY, 1995).

A pesquisa é qualitativa, apoiada em um modelo descritivo. É qualitativa porque busca um melhor entendimento de um fenômeno a ser posteriormente analisado de forma abrangente, razão pela qual os pesquisadores foram a campo verificar as perspectivas dos envolvidos, considerando seus pontos de vista mais relevantes (GODOY, 1995). É descritiva porque busca enumerar as características da população alvo e do fenômeno objeto de estudo 
(GIL, 2008). Tem como motivação central as razões de escolha para o ingresso no curso de Ciências Contábeis na cidade de São Paulo.

Os procedimentos metodológicos iniciaram com uma pesquisa bibliográfica. Esta etapa da investigação permitiu obter os elementos necessários para construir a base teórica sobre as escolhas de carreira e profissão e sobre as possíveis atuações do contador formado. Optou-se por realizar entrevistas de profundidade (VERGARA, 2009, p.52), um procedimento com o qual se fazem perguntas a pessoas que, oralmente, as respondem. Houve a interação entre entrevistadores e entrevistados durante a entrevista.

A análise de conteúdo é um método empírico, dependente do tipo de fala a que se dedica e do tipo de interpretação que se pretende como objetivo (BARDIN, 2009). De forma geral, considera-se que a sutileza dos métodos empregados para a análise de conteúdo permite a superação da incerteza e o enriquecimento da leitura. Do ponto de vista metodológico, buscou-se confrontar e posteriormente completar duas orientações: a verificação prudente ou a interpretação brilhante. A análise de conteúdo mede o conteúdo semântico ou o aspecto "o quê" da mensagem. Sua amplitude faz dela uma ferramenta flexível e vasta, que pode ser usada como uma metodologia ou como uma técnica para um problema específico (COOPER, SCHINDLER, 2003, p. 346).

O roteiro de entrevista está apresentado no apêndice. Este instrumento de coleta de dados de campo foi elaborado com base na revisão da literatura, sendo dividido em duas partes: a primeira contém perguntas voltadas para identificar o perfil sócio-econômico dos entrevistados; a segunda possui questões que buscaram identificar os fatores que influenciaram a escolha pelo curso de Ciências Contábeis.

Os achados e sua análise estão circunscritos à amostra objeto da pesquisa. Como já informado, pretende-se, após esta etapa da investigação, ampliar o tamanho de amostra e a quantidade de pontos a investigar. Somente após realizar a segunda etapa de pesquisa será possível constatar igualdades ou diferenças de percepção entre as amostras de sujeitos de pesquisa.

\section{APRESENTAÇÃO E DISCUSSÃO DOS RESULTADOS}

Os resultados encontrados permitiram traçar um perfil dos ingressantes no curso de Ciências Contábeis. Parte dos achados apresenta a situação social e econômica dos alunos. Outra parte evidencia as perspectivas desses sujeitos, as ideias e conceitos por eles 
concebidos. Alguns resultados corroboram parte da literatura pesquisada; parte vai de encontro às demais referências.

Dos sete entrevistados, um teve a entrevista descartada após informar o trancamento do curso. Das entrevistas restantes verificou-se a predominância feminina dos respondentes, fato que chama a atenção, pois, atualmente, apenas $32 \%$ dos contadores registrados no estado de São Paulo são mulheres (CRC-SP, [2012]) Pesquisa similar realizada no município de Afonso Claudio-ES, obteve maioria de mulheres entrevistadas, com 65\% (DUMER; SOUZA, 2012). Os sujeitos da PUC-SP são mais novos que os da FECAP. A maioria dos respondentes (66\%) teve um intervalo menor de três anos entre a conclusão do ensino médio e o ingresso na graduação. As respostas às primeiras questões estão no Quadro 1.

\begin{tabular}{|c|c|c|c|c|c|c|c|}
\hline IES & Sujeito & Idade & Gênero & $\begin{array}{c}\text { Conclusão } \\
\text { ensino } \\
\text { médio }\end{array}$ & $\begin{array}{l}\text { Origem } \\
\text { escolar }\end{array}$ & $\begin{array}{c}\text { Estado } \\
\text { civil }\end{array}$ & Renda familiar \\
\hline \multirow{3}{*}{$\begin{array}{l}\tilde{n} \\
\bigcup^{1} \\
\text { 2 }\end{array}$} & A & 17 & Feminino & 2011 & Pública & Solteiro & Entre $R \$ 1.500$ e $R \$ 3.000$ \\
\hline & B & 20 & Feminino & 2009 & Pública & Solteiro & Acima de $\mathrm{R} \$ 5.000$ \\
\hline & $\mathrm{C}$ & 19 & Feminino & 2010 & Pública & Solteiro & Entre $R \$ 1.500$ e $R \$ 3.000$ \\
\hline \multirow{3}{*}{ 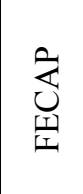 } & $\mathrm{D}$ & 19 & Feminino & 2010 & Particular & Solteiro & Acima de $R \$ 5.000$ \\
\hline & E & 25 & Masculino & 2004 & Particular & Solteiro & Acima de R\$5.000 \\
\hline & $\mathrm{F}$ & 30 & Masculino & 2000 & Pública & Solteiro & Entre $\mathrm{R} \$ 1.500$ e $\mathrm{R} \$ 3.000$ \\
\hline
\end{tabular}

Quadro 1 dados demográficos

Fonte: dados da pesquisa

Dois terços dos entrevistados provêm de escola pública, corroborando com os dados do INEP (2009) no Censo da Educação Superior. Todos os entrevistados da PUC-SP provêm de escolas públicas, ajudando a compreender melhor os dados do Quadro 2, no qual verificase que a maioria dos alunos oriundos de escolas públicas financia seu curso usando o FIES ou recebe incentivo governamental por meio do PROUNI (programa governamental no qual o governo federal custeia o curso superior do aluno). Apenas um entrevistado cumpre suas obrigações financeiras com a IES usando renda própria.

Os respondentes que financiam os estudos ou possuem incentivos financeiros afirmaram possuir renda familiar entre $\mathrm{R} \$ 1.500,00$ e $\mathrm{R} \$ 3.000,00$. Considerado o fato de que o valor médio da mensalidade do curso nas duas IES pesquisadas é superior a R\$1.000,00 (um mil reais), compreende-se a necessidade de financiamento/custeamento ou incentivo 
financeiro dos estudos por parte destes alunos. Na sequência, foram tabulados e analisados os dados econômicos, sintetizados no Quadro 2.

\begin{tabular}{|c|c|c|c|c|c|c|}
\hline IES & Sujeito & $\begin{array}{c}\text { Financiamento } \\
\text { do curso }\end{array}$ & $\begin{array}{c}\text { Escolaridade } \\
\text { pai }\end{array}$ & Ocupação pai & $\begin{array}{l}\text { Escolaridade } \\
\text { mãe }\end{array}$ & $\begin{array}{c}\text { Ocupação } \\
\text { mãe }\end{array}$ \\
\hline \multirow{3}{*}{$\begin{array}{l}\tilde{n} \\
\text { Uे } \\
\text { D }\end{array}$} & A & PROUNI & Médio & Tintureiro & Superior & Secretária \\
\hline & B & Próprio/Pais & Médio & $\begin{array}{c}\text { Gerente de } \\
\text { telecomunicaç } \\
\text { ões }\end{array}$ & Médio & Aposentada \\
\hline & $\mathrm{C}$ & PROUNI & Médio & Autônomo & Fundamental & Autônoma \\
\hline \multirow{3}{*}{ 密 } & $\mathrm{D}$ & Pais & Fundamental & Comerciante & Fundamental & Comerciante \\
\hline & $E$ & Próprio & Fundamental & Empresário & Médio & Empresária \\
\hline & $\mathrm{F}$ & FIES & Fundamenta & $\begin{array}{l}\text { Mecânico de } \\
\text { manutenção }\end{array}$ & Fundamental & Falecida \\
\hline
\end{tabular}

Quadro 2 dados econômicos

Fonte: dados da pesquisa

Quanto à escolaridade dos pais dos entrevistados, constatou-se que metade de suas mães e pais cursou apenas o ensino fundamental. Entre os pais, a outra metade possui escolaridade até o ensino médio. Entre as mães, apenas uma possui ensino superior (em Administração de Empresas) Constatou-se variedade quanto à ocupação dos pais. Prevaleceram atividades empreendedoras: empresários, comerciantes e autônomos, como se vê no Quadro 2. Os resultados com a amostra apontam que nem a escolaridade e tampouco a ocupação dos pais influenciou os alunos na profissão escolhida, o que vai de encontro à pesquisa realizada por Almeida e Pinho (2008).

Concluído o levantamento sócio-econômico, passou-se para as questões relacionadas aos fatores que motivaram a escolha pelo curso de Ciências Contábeis. Dos seis entrevistados, um ainda não havia prestado outro vestibular (sujeito A). Três respondentes já haviam passado por outro curso superior (sujeito B - Direito; sujeito F - Economia; sujeito E Hotelaria). Destes, somente o sujeito E havia concluído o curso.

Os outros dois trocaram os cursos que frequentavam pelo de Ciências Contábeis. Um número cada vez maior de graduados tem procurado o curso de Ciências Contábeis como segunda graduação, variando entre $8 \%$ e $13 \%$ dos alunos matriculados (CORNACHIONE JUNIOR et al., 2010; CUNHA; CORNACHIONE JUNIOR; MARTINS, 2010). Algumas IES já possuem curso de graduação em Ciências Contábeis exclusivamente para o público graduado em cursos de Administração, Economia e Direito, com um período letivo menor que o curso regular. A FECAP, por exemplo, possui tal curso disponível. 
Um ponto a ser pesquisado era se os então ingressantes conheciam o curso de Ciências Contábeis antes do vestibular. Todos declararam que já conheciam tanto o curso como também a teoria ou a prática de contabilidade. Ao serem indagados se acreditavam ter as habilidades necessárias para serem bons profissionais da contabilidade e se estavam se identificando com o curso escolhido, as respostas obtidas foram unânimes em apontar positivamente.

Os achados apontam no sentido de que os alunos demonstraram convicção no momento de escolha o curso, pois sabiam, de alguma forma, qual era a atividade da contabilidade e gostavam desta atividade. Neste sentido, os resultados corroboram com a ideia de Balbinotti (2003) ao mostrar que o indivíduo tem em mente quem ele pensa ser, como também corroboram com a clareza de autoconceito citada por Super (1980) na qual o indivíduo realiza uma ligação de seus traços pessoais com seu desenvolvimento profissional.

Nenhum dos alunos entrevistados declarou ter conhecido o curso por intermédio da família, reforçando os resultados sintetizados no Quadro 2 e indo de encontro com a pesquisa realizada por Almeida e Pinho (2008). Metade dos entrevistados declarou ter conhecido a contabilidade durante sua primeira graduação. Os demais tomaram conhecimento sobre as práticas contábeis por intermédio de cursos profissionalizantes.

Um entrevistado declarou ter conhecido o curso de Ciências Contábeis ao revisar as notas de corte para ingresso nos cursos de graduação da USP. Por ser um curso com nota de corte mais baixa, decidiu por pesquisar sobre ele, identificou-se com o curso e acabou por prestar vestibular para a área. Os estudantes foram questionados se seu gosto ou habilidade por matemática influenciou na decisão pelo curso de Ciências Contábeis e apenas dois deles declararam que sim, não sendo este o quesito de maior peso.

A Resolução 560/83 apresenta as condições com as quais o profisssional de contabilidade pode exercer suas atividades, funções, cargos e titulações. Com o objetivo de verificar o conhecimento dos entrevistados sobre esta Resolução, lhes foi questionado sobre suas pretensões de carreira na área contábil. As respostas obtidas foram variadas, sendo que os alunos poderiam citar mais de uma. A opção mais citada foi de Auditor, seguida por Controller. Contador, fiscal, empresário, professor e tributarista também foram lembradas. Em pesquisa realizada por Dumer e Souza (2012), a metade dos estudantes entrevistados informou possuir pouco conhecimento da profissão contábil antes de ingressar no curso de graduação em Ciências Contábeis. 
Questionados sobre a possibilidade de a profissão contábil lhes trazer status, somente um declarou acreditar que sim. Os demais afirmaram não acreditar nessa possibilidade, por terem relatado que a profissão contábil não é valorizada ou reconhecida pela sociedade. Este achado revela o desconhecimento da valorização do profissional contábil pelos agentes econômicos como apresentam Lopes, Iudícibus e Martins (2008).

Finalmente, como fator decisivo para a escolha do curso de Ciências Contábeis, os entrevistados citaram, de formas difstintas, o mesmo ponto principal: empregabilidade. Para eles o mercado de trabalho na área contábil é amplo e aquecido, favorecendo sua inserção. Para alguns, que já atuam na área ou em áreas correlatas ou em empresas nas quais é possível atuarem na área, o curso de Ciências Contábeis facilitará seu ingresso e crescimento profissional. As respostas dos alunos concordam com as pesquisas realizadas, pois há inúmeras vagas na área contábil (PELEIAS et al., 2008; PIRES; OTT; DAMACENA, 2009). A pesquisa de Dumer e Souza (2012) aponta como principais fatores que influenciaram na escolha pelo curso de Ciências Contábeis o mercado de trabalho aquecido (42\%) e o fato dos entrevistados já atuarem na área (18\%).

A síntese das respostas dadas pelos alunos quanto à decisão de escolha pelo curso de Ciências Contábeis está apresentada no Quadro 3.

\begin{tabular}{|c|c|c|c|c|c|}
\hline IES & Sujeito & $\begin{array}{l}\text { Como tomou } \\
\text { conhecimento } \\
\text { do curso }\end{array}$ & Momento de escolha pelo curso & $\begin{array}{l}\text { Pretensões } \\
\text { de carreira }\end{array}$ & $\begin{array}{l}\text { Fator decisivo pela } \\
\text { escolha do curso }\end{array}$ \\
\hline \multirow{3}{*}{$\begin{array}{l}\tilde{0} \\
\bigcup_{2}^{2} \\
2\end{array}$} & A & Amigos & $\begin{array}{l}\text { "No curso pré-vestibular conheci e } \\
\text { contabilidade e gostei" }\end{array}$ & $\begin{array}{l}\text { Contador ou } \\
\text { Auditor }\end{array}$ & $\begin{array}{l}\text { Mercado de trabalho } \\
\text { aquecido }\end{array}$ \\
\hline & B & Trabalho & $\begin{array}{l}\text { "Estudava Direito por trabalhar } \\
\text { nesta área. Tive aulas de } \\
\text { contabilidade e gostei" }\end{array}$ & $\begin{array}{l}\text { Tributarista } \\
\text { ou Professor }\end{array}$ & Trabalho atual \\
\hline & $\mathrm{C}$ & $\begin{array}{c}\text { Curso } \\
\text { profissionalizante }\end{array}$ & $\begin{array}{l}\text { "As notas de corte do curso de } \\
\text { Ciências Contábeis eram mais } \\
\text { baixas, como já gostava de } \\
\text { humanas decidi pelo curso" }\end{array}$ & Área fiscal & $\begin{array}{l}\text { Curso } \\
\text { profissionalizante de } \\
\text { contabilidade }\end{array}$ \\
\hline \multirow{2}{*}{ 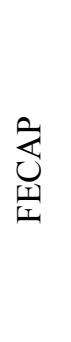 } & $\mathrm{D}$ & Contador & $\begin{array}{l}\text { "Fiz um curso profissionalizante de } \\
\text { contabilidade e resolvi fazer a } \\
\text { graduação na mesma área" }\end{array}$ & $\begin{array}{l}\text { Auditor ou } \\
\text { Controller }\end{array}$ & $\begin{array}{l}\text { Mercado de trabalho } \\
\text { aquecido e amplo }\end{array}$ \\
\hline & $\mathrm{E}$ & $\begin{array}{l}\text { Graduação em } \\
\text { Hotelaria }\end{array}$ & $\begin{array}{l}\text { "Conheci contabilidade na } \\
\text { graduação em Hotelaria. Pretendo } \\
\text { abrir uma empresa e acredito que o } \\
\text { conhecimento em contabilidade } \\
\text { poderá ajudar muito" }\end{array}$ & Empresário & $\begin{array}{l}\text { Conhecimentos que } \\
\text { só um contador } \\
\text { possui }\end{array}$ \\
\hline
\end{tabular}




\begin{tabular}{|c|c|c|c|c|c|}
\hline F & Trabalho & $\begin{array}{c}\text { "Cursando Economia me achei } \\
\text { muito velho para a área. Já que } \\
\text { trabalho com contabilidade, achei } \\
\text { que poderia ser melhor para meu } \\
\text { perfil" }\end{array}$ & $\begin{array}{c}\text { Auditor ou } \\
\text { Controller }\end{array}$ & Trabalho atual \\
\hline
\end{tabular}

Quadro 3 Decisão de escolha

Fonte: dados da pesquisa

\section{CONSIDERAÇÕES FINAIS E CONTINUIDADE DA INVESTIGAÇÃO}

A questão central desta pesquisa residiu em identificar e descrever os fatores que influenciaram a decisão de escolha pelo ingresso no curso de Ciências Contábeis em duas IES particulares da cidade de São Paulo. Considera-se que a questão foi respondida, conforme pode-se verificar no Quadro 3 e nas análises apresentadas.

Dentre os resultados obtidos, verificou-se, junto aos sujeitos desta etapa da investigação, que os fatores mais influentes para a escolha do curso de Ciências Contábeis foram o prévio conhecimento do aluno sobre a teoria ou prática da contabilidade, a visão de empregabilidade que possuem sobre a atuação do contador e a área de trabalho atual dos entrevistados. Para estes alunos, a empregabilidade pode ocorrer de duas formas: a) de forma desejosa - os alunos creem que o mercado de trabalho para o contador é aquecido e amplo, facilitando seu ingresso ou permanência; b) de forma realista - os alunos iniciaram suas carreiras trabalhando na área contábil ou em áreas correlatas e decidiram, então, por realizar o curso superior na mesma área.

Os entrevistados foram unânimes em relatar que os pais não tiveram influência direta na escolha pelo curso de Ciências Contábeis, o que foi de encontro ao constatado na revisão da literatura. Constatou-se, junto à amostra investigada, que a quase totalidade dos pais dos entrevistados não possui curso superior, apontando uma geração de pessoas que busca o crescimento pessoal e profissional realizando um curso superior. Mais da metade dos entrevistados são mulheres, um indício do crescimento do gênero feminino no curso de Ciências Contábeis. Sugere-se realizar estudos para verificar a posição e atuação das mulheres na área contábil devido ao fado de, atualmente, apenas um terço delas possuírem registro profissional no estado de São Paulo.

Foram identificadas oportunidades de melhoria no instrumento de coleta de dados. Verificou-se a possibilidade de aprofundar as questões relativas à empregabilidade e a visão dos entrevistados sobre o mundo do trabalho. Os resultados encontrados permitem a continuidade da pesquisa, de forma mais aprofundada. Espera-se, nesta continuidade, realizar 
outros tipos de análises: as razões para o crescimento do gênero feminino nos cursos de Ciências Contábeis ao longo dos anos, como também os motivos de evasão no curso. Outra sugestão é realizar o mesmo questionamento aqui apresentado em uma amostra maior para que se possam confirmar ou não os resultados aqui encontrados.

\section{REFERÊNCIAS}

ALMEIDA, F. H.; MELO-SILVA, L. L. Influência dos pais no processo de escolha profissional dos filhos: uma revisão de literatura. Psico-USF, v. 16, n. 1, p. 75-85, 2011.

ALMEIDA, M. E. G. G.; PINHO, L. V. Adolescência, família e escolhas: implicações na orientação profissional. Psicologia Clínica, Rio de Janeiro, v. 20, n. 2, p.173-184, 2008.

BALASSIANO, M.; VENTURA, E. C. F.; FONTES FILHO, J. R. Carreiras e cidades: existiria um melhor lugar para se fazer carreira? RAC, São Paulo, v. 8, n. 3, p. 99-116, jul./set. 2004.

BALBINOTTI, M. A. A. A noção transcultural de maturidade vocacional na teoria de Donald Super. Psicologia: reflexão e crítica, Porto Alegre, v. 16, n. 3, p. 461-473, 2003.

BANDURA, A. Social cognitive theory: an agentic perspective. Annual Review of Psychology, Stanford, n. 52, p. 1-26, 2001.

BARDIN, L. Análise de Conteúdo. (tradução de Luís Antero Reto e Augusto Pinheiro). Lisboa: Edições 70, LDA., 2009.

BOHOSLAVSKY, R. Orientação Vocacional: a estratégia clínica. 9. ed. São Paulo: Martins Fontes, 1995.FILOMENO, K. Mitos familiares e escolha profissional: uma visão sistêmica. São Paulo: Vetor, 1997.

BOMTEMPO, M. Análise dos fatores de influência na escolha pelo curso de graduação em Administração: um estudo sobre as relações de causalidade, através da modelagem de equações estruturais. 2005. 142 p. Dissertação (Mestrado em Ciências Contábeis)-Fundação Escola de Comércio Álvares Penteado - FECAP, São Paulo: 2005.

BRASIL. Decreto n. 9.295, de 27 de maio de 1946. Cria o Conselho Federal de Contabilidade, define as atribuições do Contador e do Guarda-livros, e dá outras providências. Disponível em: <http://www.planalto.gov.br/ccivil_03/Decreto-Lei/Del9295.htm>. Acesso em: 25 set. 2012.

BRASIL. Lei n. 9.394/96, de 20 de dezembro de 1996. Estabelece as diretrizes e bases da educação nacional. Disponível em: <http://www.planalto.gov.br/ccivil_03/leis/L9394.htm>. Acesso em: 27 fev. 2013.

BURNETT, S. The future of accounting education: a regional perspective. Journal of education for business, Washington, v. 78, n. 3, jan./fev. 2003. 
BYALIN, K. The concept of profession. In: Eastern Sociological Society, 50., 1980, New Jersey.

CHANLAT, J. Quais carreiras e para qual sociedade? (I) RAE - Revista de Administração de Empresas, São Paulo, v. 35, n. 6, p. 67-75, nov./dez. 1995.

CONSELHO FEDERAL DE CONTABILIDADE- CFC. Resolução n. 560, de 28 de outubro de 1983. Dispõe sobre as prerrogativas profissionais de que trata o artigo 25 do Decreto-lei n. 9.295, de 27 de maio de 1946. Disponível em:

<http://www.cfc.org.br/sisweb/sre/docs/RES_560.doc>. Acesso em: 25 set. 2012.

COOPER, D.R., SCHINDLER, P.S., Métodos de pesquisa em administração. 7. ed., Porto Alegre: Bookman, 2003.

CORNACHIONE JUNIOR, E. B., CUNHA, J. V. A.; DE LUCA, M. M. M.; OTT, E. O bom é meu, o ruim é seu: perspectivas da teoria da atribuição sobre o desempenho acadêmico de alunos da graduação em Ciências Contábeis. Revista Contabilidade \& Finanças - USP, São Paulo, v. 21, n. 53, maio/ago. 2010.

CRC-SP MULHER. Quem somos. [2012]. Disponível em $<$ http://www.crcsp.org.br/portal_novo/hotsite/mulher_contabilista/quem_somos.htm>. Acesso em: 28 fev. 2013.

CUNHA, J. V. A., CORNACHIONE JUNIOR, E. B., MARTINS, G. A. Doutores em Ciências Contábeis: análise sob a óptica da teoria do capital humano. RAC, Curitiba, v. 14, n. 3, p. 532-557, maio/jun. 2010.

DIAS, E. C. M.; THEÓPHILO, C. R.; LOPES, M. A. S. Evasão no ensino superior: estudo dos fatores causadores da evasão no curso de Ciências Contábeis da Universidade Estadual de Montes Carlos - UNIMONTES - MG. In: CONGRESSO USP CONTROLADORIA E CONTABILIDADE, 10., 2010, São Paulo. Anais eletrônicos... São Paulo: FEA-USP, 2010. Disponível em: <http://www.congressousp.fipecafi.org/artigos102010/419.pdf >. Acesso em: 14 out. 2012.

DUMER, M. C. R.; SOUZA, A. L. Percepções de graduandos em Ciências Contábeis sobre o curso escolhido, mercado de trabalho e órgãos de classe. Revista Brasileira de Contabilidade, Brasília, ano 41, n. 197, p. 21-33, 2012.

E-MEC. Instituições de Educação Superior e cursos cadastrados. [2013]. Disponível em: $<$ http://emec.mec.gov.br/>. Acesso em: 27 fev. 2013.

FLECK, A. C.; WAGNER, A. A mulher com principal provedora do sustento econômico familiar. Psicologia em estudo. v. 8, n. esp., p. 31-38, 2003.

FUNDAÇÃO CARLOS CHAGAS - FCC. Banco de dados sobre o trabalho das mulheres. Disponível em: <http://www.fcc.org.br/bdmulheres/>. Acesso em: 29 mar. 2013.

GIL, A. C. Métodos e técnicas de pesquisa social. 6. ed. São Paulo: Atlas, 2008. 
GODOY, A. S. Pesquisa qualitativa: tipos fundamentais. ERA - Revista de Administração de Empresas, São Paulo, v. 35, n. 3, p. 20-29, maio/jun. 1995.

INSTITUTO NACIONAL DE ESTUDOS E PESQUISAS EDUCACIONAIS ANÍSIO TEIXEIRA - INEP. Resumo técnico: censo da educação superior de 2009. Brasília, 2010. Disponível em: <http://portal.inep.gov.br/web/censo-da-educacao-superior/resumostecnicos>. Acesso em: 25 set. 2012.

INSTITUIÇÕES de Educação Superior e cursos cadastrados. E-Mec, 2013. Disponível em: $<$ http://emec.mec.gov.br/>. Acesso em: 27 fev. 2013.

KHOURY, R. M. The "profession" concept: areas of agreement. In: Southern Sociological Society, 1978, Georgia.

KOLLING, F.; BIEGER, M.; SEIBERT, R. M. Inserção da mulher no mercado de trabalho contábil. Contabilidade e Informação. Rio Grand do Sul, v. 13, n. 32, p. 81-88, jan./jun. 2010 .

LENT, R. W.; BROWN, S. D.; HACKETT, G. Toward a unifying social cognitive theory of career and academic interest, choice, and performance. Journal of Vocational Behavior, Ohio, v. 45, n. 1, p. 79-122, ago. 1994.

LOPES, A. B.; IUDÍCUBUS, S.; MARTINS, E. Sobre a necessidade de se estudar contabilidade e (e não ou) finanças. Revista Contabilidade \& Finanças - USP. São Paulo, v. 19, n. 47, editorial, maio./ago. 2008.

LÜDKE, M.; BOING, L. A. Caminhos da profissão e da profissionalidade docentes. Revista Educação \& Sociedade. Campinas, v. 25, n. 89, p. 1159-1180, set./dez. 2004.

MORAES, J. O.; THEÓPHILO, C. R. Evasão no ensino superior: estudo dos fatores causadores da evasão no curso de Ciências Contábeis da Universidade Estadual de Montes Claros - UNIMONTES. In: CONGRESSO USP INICIAÇÃO CIENTÍFICA EM

CONTABILIDADE, 3., 2006, São Paulo. Anais eletrônicos... São Paulo: FEA-USP, 2006. Disponível em: $<$ http://www.congressousp.fipecafi.org/artigos32006/370.pdf $>$. Acesso em: 14 out. 2012.

MOURA, C. B.; SILVEIRA, J. M. Orientação profissional sob o enfoque da análise do comportamento: avaliação de uma experiência. Revista Estudos de Psicologia, Campinas, v. 19, n. 1, p. 5-14, jan./abr. 2002.

NUNES, M. F. O.; NORONHA, A. P. P. Modelo sócio-cognitivo para a escolha de carreira: o papel da auto-eficácia e de outras variáveis relevantes. Educação Temática Digital, Campinas, v. 10, n. esp. P. 16-35, out. 2009.

PIRES, C. B.; OTT, E.; DAMACENA, C. "Guarda-Livros" ou "Parceiros de Negócios"? Uma análise do perfil profissional requerido pelo mercado de trabalho para contadores na região metropolitana de Porto Alegre (RMPA). Revista Contabilidade Vista \& Revista, Belo Horizonte, v. 20, n. 3, p. 157-187, jul./set. 2009. 
PELEIAS, I. R.; SILVA, G. P.; SEGRETTI, J. B.; CHIROTO, A. R. Evolução do ensino da contabilidade no Brasil: uma análise histórica. Revista Contabilidade \& Finanças - USP. v. edição 30 anos de doutorado. p. 19-32, jun. 2007.

PELEIAS, I. R.; GUIMARÃES, P. C.; SILVA, D.; ORNELAS, M. M. G. Identificação do perfil profissiográfico do profissional de contabilidade requerido pelas empresas, em anúncios de emprego na região metropolitana de São Paulo. Base - Revista de Administração e Contabilidade da Unisinos, Porto Alegre, v. 5, n. 2, p. 131-141, maio/ago. 2008.

PELEIAS, I. R.; MENDONÇA, J. F.; SLOMSKI, V. G.; FAZENDA, I. C. A. Interdisciplinaridade no ensino superior: análise da percepção de professores de controladoria em cursos de Ciências Contábeis na cidade de São Paulo. Avaliação, Campinas, v. 16, v. 3, p. 499-532, nov. 2011.

PINHEIRO, R. G. Fatores de escolha pelo curso de Ciências Contábeis - uma pesquisa com os graduandos na capital e Grande São Paulo. 2008. 99 f. Dissertação (Mestrado em Ciências Contábeis)-Fundação Escola de Comércio Álvares Penteado - FECAP, São Paulo: 2008.

SANTOS, L. M. M. O papel da família e dos pares na escolha profissional. Psicologia em Estudo, Maringá, v. 10, n. 1, p. 57-66, jan./abr. 2005.

SILVA FILHO, R. L. L. S.; MONTEJUNAS, P. R.; HIPÓLITO, O.; LOBO, M. B. C. M. A evasão no ensino superior brasileiro. Cadernos de Pesquisa, São Paulo, v. 37, n. 132, p. 641 659, set./dez. 2007.

SOUSA, S. G. Escolha, carreira e inserção profissional: desafios do mundo do trabalho. Revista Brasileira de Orientação Profissional, Ribeirão Preto, v. 8, n.2, p. 93-96, 2007.

SUPER, D. E. A life-span, life-space approach to career development. Journal of Vocation Behavior, Ohio, v. 16, n. 3, p. 282-298, jun., 1980.

TEIXEIRA, M. A. P.; GOMES, W. B. Estou me formando... e agora? Reflexões e perspectivas de jovens formandos universitários. Revista Brasileira de Orientação Profissional, Ribeirão Preto, v. 5, n. 1, p. 47-62. 2004.

TEIXEIRA, M. A. P.; GOMES, W. B. Decisão de carreira entre estudantes em fim de curso universitário. Psicologia: Teoria e Pesquisa, Brasília, v. 21, n. 3, p. 327-334, set./dez. 2005.

UYAR, A.; GÜNGÖRMÜS, A. H.; KUZEY, C. Factors affecting students' career choice in accounting: the case of a Turkish University. American journal of business education, Littleton, v. 4, n. 10, 29-38, out. 2011.

VERGARA, S. C. Projetos e relatórios de pesquisa em administração. 10ª ed. São Paulo: Atlas, 2009.

YUSOFF, Y.; OMAR, Z. A.; AWANG, Y.; YUSOFF, R.; JOSOFF, K. Does knowledge on professional accounting influence career choice? Word Applied Sciences Journal 12 (Special Issue on Bolstering Economic Sustainability), Malaysian, p. 57-60, 2011. 


\section{APÊNDICE}

Roteiro da entrevista realizada com os alunos:

1) Em qual faculdade estuda: ( ) PUC-SP ou ( ) FECAP

2) Qual a sua idade?

3) Qual seu sexo: ( ) feminino ( ) masculino

4) Em que ano se formou no ensino médio?

5) Cursou o ensino médio em escola pública ou particular?

6) Qual seu estado civil?

7) De que forma você paga a faculdade: ( ) renda própria ( ) renda dos pais ( ) PROUNI ( ) FIES

8) Trabalha em atividade remunerada? $\mathrm{Na}$ área contábil?

9) Qual a renda média da família: ( ) até $\mathrm{R} \$ 1.500,00$ ( ) entre $\mathrm{R} \$ 1.500,00$ e $\mathrm{R} \$$ 3.000,00 ( ) entre R \$ 3.000,00 e R \$ 5.000,00 ( ) acima de R \$ 5.000,00

10) Qual a escolaridade de sua mãe?

11) Qual a escolaridade de seu pai?

12) Qual a ocupação de seus pais?

13) Possui outro curso superior?

14) Como você tomou conhecimento sobre o curso de Ciências Contábeis?

15) A habilidade ou gosto por fazer contas ou matemática foi um fator relevante na escolha pelo curso?

16) Em que momento você decidiu que seria um contador (a)?

17) Você conhece as atividades e práticas da profissão contábil?

18) Quais suas pretensões de carreira?

19) Você acha que a profissão contábil irá te trazer status?

20) Você acredita que tenha as habilidades necessárias para ser um bom profissional?

21) Qual fator você diria ser o mais importante na sua escolha pelo curso? 